\title{
Awareness and outreach
}

\author{
Suzanne J Farley
}

Nephrologists are constantly reminded of the ever-increasing incidence of type 2 diabetes. Physicians are rightly concerned that the existing therapeutic armamentarium and nephrological services will be unable to cope with the burden of diabetic renal disease that is projected to develop. Urgent emphasis is now being placed on early detection and prevention of diabetic nephropathy, and chronic kidney disease in general. Initiatives such as World Kidney Day_inaugurated in March 2006-aim to raise awareness of the scale of the problem.

Many of the factors that underlie development of type 2 diabetes are particular to Western nations. The relative affluence of these countries grants their citizens access to lifestyle choices that, despite being perceived as making life 'easier', are actually detrimental to health and wellbeing. Fast food, efficient forms of transport and mechanization of tasks that previously required expenditure of physical energy have contributed to an epidemic of obesity and the metabolic syndrome, which in turn drive development of type 2 diabetes, diabetic nephropathy and end-stage renal disease.

Type 2 diabetes is just one of many clinical entities with renal implications that develop in response to lifestyle choices in the West. The Case Study by Kalantar-Zadeh and colleagues in this issue of Nature Clinical Practice Nephrology describes management of another-hyponatremia following ingestion of the 'party' drug ecstasy.

It is clear that we know a lot about kidneyrelated disorders that affect patients in developed nations. But what about developing countries? Does the 'profile' of causes underlying renal disease differ in developed and developing nations? Are these questions even relevant to the majority of nephrologists?

I believe that the answer to the latter question is 'yes', for two reasons. First, increasing rates of international travel and immigration are resulting in physicians encountering clinical entities with which they are unfamiliar. Editors at Nature
HINARI

currently

grants 113

institutes in

developing

countries full

online access

to more

than 3,200

biomedical

titles, including

the Nature

Clinical

Practice series

SJ Farley is Editor

of Nature Clinical

Practice Nephrology.

Competing interests

The author declared she has no competing interests.

www.nature.com/clinicalpractice doi:10.1038/ncpneph0168
Clinical Practice Nephrology work hard to commission articles that provide insight into such cases. In this issue, the Review on viral nephropathy by Kar Neng Lai and Andrew Lai includes sections on pathogens such as the coronavirus that causes severe acute respiratory syndrome. Upcoming articles will examine the role of plant and animal toxins in acute renal failure.

Second, the relatively privileged status of physicians in developed nations places them in the unique position of being able to share expertise and resources with their counterparts in less affluent countries. The International Society of Nephrology — with which Nature Clinical Practice Nephrology is affiliated-has developed several initiatives to encourage such collaboration. Renal Sister Centers, the Fellowship Program (see the Editorial in the February issue of the journal) and World Kidney Day (in conjunction with the International Federation of Kidney Foundations) are just a few examples.

Disease management strategies must be tailored to the specific needs of developing nations, rather than simply being 'imported' from the West. High-quality research is the backbone of developing effective interventions, and researchers in the countries in which strategies will eventually be implemented are best placed to conduct it. But again, access to resources is a barrier to progress.

In this regard, Nature Publishing Group is helping, by providing free access to its journals through the Health InterNetwork Access to Research Initiative (HINARI). Established by the WHO, HINARI currently grants 113 institutes in developing countries full online access to more than 3,200 biomedical titles, including the Nature Clinical Practice series.

At the individual level, I have been gratified to receive requests from peer reviewers and authors-who receive a complimentary subscription to Nature Clinical Practice Nephrology-that their subscription be donated to a researcher in a developing nation. Obviously, the message is getting through. 